\title{
Developing a First Nation community skills inventory ${ }^{1}$
}

\section{Devon MacKinnon-Ottertail}

First Nation communities have been presented a stronger role in mining and forestry developments by recent court judgements on governments' duty to consult. Negotiations with mining companies have often included employment for community members in any Memorandum of Understanding (MOU). When jobs are presented by mining companies, the forestry industry, and other employers, there is no current system for First Nation Administrators to determine if community members have the pre-requisite skills, experience and qualifications that the employer is looking for and this has led to missed opportunities.

To act on these prospects, Eagle Lake First Nation (ELFN) developed a system for tracking any training offered by the Band and created a skills inventory for additional training and certifications that community members have completed either on-reserve or off-reserve. This paper will document the development of this system.

Keywords: First Nations, employment, recruitment, human resources, skills, community skills inventory, Ontario, Canada.

First Nation communities have been presented a stronger role in mining and forestry developments by recent court judgements on governments' duty to consult. As part of the consultation process, mining and forestry companies have a duty to consult surrounding First Nation communities when industry activities may impact the land. With lands and resource issues at the forefront, negotiations with mining companies have often included employment for community members in any Memorandum of Understanding (MOU). When jobs are presented by mining companies, the forestry industry, and other employers, there is no current system for First Nation Administrators to determine if community members have the pre-requisite skills, experience and qualifications that the employer is looking for and this has led to missed opportunities. The issue is whether the people will be employable when these opportunities arise and whether the community is able to negotiate realistic employment prospects based on accurate data.

To act on these prospects, Eagle Lake First Nation (ELFN) developed a system for tracking any training offered by the Band and created a skills inventory for additional training and certifications that community members have completed either on-reserve or off-reserve. This paper will document the development of this system.

\section{Study area}

\footnotetext{
${ }^{1}$ Editor's note: This paper was written in 2014.
} 
Eagle Lake First Nation has an on-reserve population of 268 and a membership of 589. Migisi Sahgaigan $^{2}$ (the Ojibway translation of Eagle Lake) is located 30km southwest of Dryden, Ontario and is situated in the Grand Council Treaty \#3 territory.

As is common with many First Nation reserves, the largest employer is the Band itself. Leadership consists of three Councilors and one Chief. At the time of this initiative, administration involved in employment matters included:

- Human Resources: Accepted resumes for internal job postings and coordinated the hiring process. The hiring process includes screening applicants, recruiting a hiring committee, organizing interviews and making the final recommendation to Leadership.

- Employment Counsellor: assisted members with creating resumes and applying for external posted jobs. This service was limited to Ontario Works clients, based on funding.

- Economic Development/Lands \& Resources: From April 2012 to December 2012, the EDO managed both departments. Neither role had interaction with community members and worked mainly with business leaders, industry partners and various levels of government. Eventually, a coordinator took over the Lands department in 2013.

There was a gap in services at the administration level with no staff working with community and band members who were underemployed and seeking better employment, those temporarily unemployed, those not eligible as an Ontario Works client, or new graduates (secondary and post-secondary).

\section{The need}

In July of 2012, a meeting was held between ELFN Leadership and a Manitoba company called Running Deer Resources (RDR). The company's president, Mr. Jamie Saulnier, presented the Community Resource Information System (CRIS) ${ }^{3}$ that his company developed in response to a difficulty in engaging First Nation communities. RDR's parent company, RDR Industrial Contractors, is a large, industrial company specializing in mining and mineral processing, providing a full range of services from capital construction projects to shut down maintenance including, mechanical, electrical, structural and fusion services. When RDR Industrial Contractors would secure a contract, Mr. Saulnier would try to reach out to the surrounding First Nation communities to hire qualified members of the community. There were often various issues that would divert RDR Industrial Contractors from hiring locally. The issues included:

- not being directed to a single point of contact,

- not getting calls returned,

\footnotetext{
${ }^{2}$ Migisi Sahgaigan is both the Ojibway translation of "Eagle Lake" and the official name of the community to avoid confusion with the other Eagle Lake First Nations in Canada. Eagle Lake First Nation can also be referred to as ELFN and Eagle Lake Band No. 27.

${ }^{3}$ CRIS will be referred to throughout the paper as ELFN's skills inventory project, process and database.
} 
- contacts not responding before contract initiation, and

- receiving resumes that did not meet the minimum requirements of the company.

Recognizing that the aboriginal workforce was one of the fastest growing segments in Canada, Mr. Saulnier developed an aboriginal engagement consulting branch of his company, thus creating RDR. The CRIS database and software was developed over the course of 6 years. Internally, it was tested but RDR was looking to connect with a pilot community.

Mr. Saulnier approached ELFN because of a previous personal and professional relationship with Chief Arnold Gardner (elected April 2012). Meanwhile, RDR was in negotiations with Bimose Tribal Council ${ }^{4}$ on a contract to incorporate CRIS into their nine member communities. Bimose submitted a proposal budget to a federal funding agent for over $\$ 1 \mathrm{M}$, including administration and internal fees. Once funding was secured, they were going to select one of their member communities to be the pilot site. Since the Bimose project was dependent on funding and there was no guarantee that ELFN would be selected as the regional pilot site, ELFN decided to independently apply to Aboriginal Affairs and Northern Development Canada (AANDC) for modest funding to pursue its own CRIS project. With an individual AANDC request, ELFN developed a CRIS proposal specific to the community's needs. It was understood that ELFN's scope wouldn't be as expansive as Treaty \#3 or the Bimose catchment area but Leadership saw the merit in the CRIS program and wanted to become champions for RDR's Aboriginal Consulting services.

\section{Funding proposal}

There were two stages as per the AANDC 2012-13 Community Economic Opportunities Programs (CEOP). For the first, a Statement of Intent was submitted by ELFN in late July of 2012. ELFN received an invitation to submit the second stage, a full CEOP application, in August. The preparation of the CEOP application was completed primarily by ELFN. RDR and Mr. Saulnier had limited experience with aboriginal funding agencies and proposal development. Mr. Saulnier was able to offer an insightful perspective as an employer but the overall goals and objectives were that of the community. RDR's role was primarily to contribute their established tools and processes, saving time and resources over building an inventory from scratch.

The application emphasized that building a community-based skills inventory with the resumes, certifications, education levels and training of community members would produce invaluable information. It proposed that the CRIS would identify those who are able to enter the workforce and those who may need education and training upgrades. Statistics would be generated for economic development purposes to identify future training opportunities by utilizing a realistic and current snapshot of the community skill level. Expiration dates of certifications would also be flagged so that upgrades and refreshers could be coordinated. Education levels would be

\footnotetext{
${ }^{4}$ Bimose Tribal Council serves as a non-political Chiefs Council which provides support and advisory services to 9 First Nation communities in the Treaty \#3 area.
} 
assessed for future and potential courses that could be offered through ELFN's partnership with Seven Generations Education Institute.

With this information, gathered and maintained by the ELFN Economic Development Manager (EDO), this information would be accessed to determine reasonable and attainable community projects and business ventures based on community skill level. This data could also be utilized for strategic planning and within a comprehensive community profile.

The CRIS application submitted to AANDC had a budget of $\$ 32,000$ with a $20 \%$ contribution from the community and a timeline of 3.5 months (late September to mid-December). The proposed key activities of the CRIS project were:

- Meeting with community leaders and Project Lead (EDO) for a review of project plan and initiatives, including setting deliverables and goals for CRIS; outlining a training schedule; and setting dates for the community feast to introduce the project, Career Fair and start-date for community member interviews.

- Planning a community feast and gathering hosted by ELFN and RDR to present to the community, explain the process and introduce the project. Advertising would be done through posters throughout the community, radio, schools/daycare, the community website and Facebook page, and through word of mouth to members and clients.

- Having RDR train the EDO on the system to be responsible for long-term updating and maintaining. They would learn about the database functionalities, the interview process, and the best strategies for data gathering.

- Rolling out the Community Program with a Career Fair and community interviews. The RDR team would host the event, while the EDO would be involved to implement the interview process.

- Assessing the response and conducting door to door interviews, if necessary, to gather further information.

- Planning a second gathering to discuss next steps and results with the community.

- Having a website developed by RDR to showcase Eagle Lake community members who are ready to work and advertise the skills inventory. RDR and ELFN would implement a marketing strategy to showcase the site and the community to industry leaders. Eagle Lake would take ownership of the database and be responsible for future upgrades and maintenance.

\section{Approval}

When applying to AANDC for the 2012-16 Community Economic Development Plan in May 2012, after the full CEOP application was submitted, a letter was received that indicated that the CRIS project could start as early as June 2012, once the application was formally approved. It was assumed that the approval would follow shortly, especially after a conversation with the regional AANDC contact who said that it should be processed quickly based on the modest 
amount of funding requested. However, the CRIS project was only approved by AANDC six months later in February 2013. In those six months, there was a consistent stream of communication between Leadership, RDR and the EDO. The AANDC contact informed ELFN that no regional projects were being approved during this time and that the funding hold was due to internal reasons. All partners were anxious to get started on CRIS so the EDO kept all partners informed during this period.

Meanwhile in November 2012, ELFN was informed by the Ministry of Northern Development \& Mines that they were approved for two Northern Communities Investment Readiness (NCIR) projects. This is the first time that the community had applied for NCIRs. ELFN had applied with another consulting firm but had since ceased that relationship. Instead, RDR was offered the contracts and accepted. RDR completed both NCIR projects: a Community Profile that was designed to eventually encompass the CRIS data and a Broad-Based Market Study that identified mining, forestry and potential business ventures to pursue but mainly focused on ELFN's nonoperational tourist resort. This activity was important to keep RDR consultants engaged with our community while waiting for the AANDC funding to be secured.

Funding from Patricia Area Community Endeavours (PACE), the local Community Futures Development Corporation, was used to offset the band's contribution to the NCIR and CRIS projects. PACE is funded by FedNor. The total funding secured from PACE was $\$ 5,000$ through their Local Initiatives Funding (LIF) program. ${ }^{5}$

When the CRIS funding was finally approved on February $19^{\text {th }}$, a project end date of March 31 was given by AANDC. Within that week, ELFN sent a formal letter to AANDC requesting an extension to the 2013-14 fiscal year. The activities identified in the four month work plan were already accelerated and the timeframe when RDR and the EDO could dedicate concentrated time towards CRIS had already passed. ELFN requested a total of six months to accommodate the coinciding community projects, employment programs, and RDR construction contracts. AANDC approved the extension.

\section{Implementation}

CRIS initiated in late February with a community information session. The session lasted three hours and had 45 attendees. It was an informal presentation in which members (community and band) were invited to ask questions. Some members had participated in a similar activity a few years ago with an outside organization and asked what happened with that venture. The company gathered resumes and it seems that no members were ultimately hired.

The difference with the CRIS system was the fact that the information and database was stored on-reserve and managed by the EDO. This is why the CRIS program was chosen by ELFN.

\footnotetext{
${ }^{5}$ Local Initiative Funding has since been discontinued by FedNor. The program was phased out by PACE by September 2013.
} 
Often, the community gives consultants or outside agencies information but it is only used to serve the purpose of the consultant/agency or their own funding proposals. This was an opportunity to present this to the membership to assure them that RDR was going to instruct on using the database, then retreat, and ELFN would continue managing and maintaining the database. 35 members signed up for interviews that were going to be held at the Band Office the next week. Interviewees were given an information sheet that included a form that would capture a majority of the information needed to input into the system and a checklist of items that they would need to bring (current resume, trades certificates, diplomas and safety certificates). The items brought to the interview were scanned and uploaded to the database. Filling out the forms prior to the interview allowed for more discussion on a major component of the database, which was the Action Plan. The Action Plan captured the participant's long-term goals and opportunities for the Band to assist them in reaching these goals.

ELFN made many recommendations throughout the process that were eventually incorporated into the CRIS database program. Participants needed to have a functional resume that could be used in their own individual job search. The original CRIS program generated a uniform resume with the band logos. The objective of the job seeker wasn't included and it generated into a PDF which excluded the opportunity to edit. This was not an appropriate format for a job seeker to submit to a potential employer. RDR updated the system to suit the needs of ELFN.

Mr. Saulnier was present the first week, which had 25 interviews. After that time, the EDO completed the following interviews. Between March and June, the EDO collected 75 resumes from band and community members. This represents approximately $53 \%$ of working age members living on-reserve (18-59). Mr. Saulnier, said that as an employer, he would hire almost every member that he interviewed and was astonished at the skill level and experience of the community.

An important component of this stage was ensuring members could see the long term benefits for themselves and their family members. It wasn't enough for the Band to develop this database of member information and not pursue employment for those who participated. There was some confusion from members during the interview process when Mr. Saulnier would present specific regional construction projects that his company was bidding on. Members left assuming they were applying for that particular job. After Day 2 of interviews, the EDO requested that specific (and unconfirmed employment) prospects not be presented but to impart that the information gathered would be used to negotiate numerous jobs with various employers.

Throughout the process and with the compressed timeline, a website (Eagle Lake Development Corporation, 2013) was designed for Eagle Lake Development to showcase member profiles. The EDO composed all of the website verbiage and earlier that year, had assisted a young man from the community in writing his business plan so he was hired to populate the site with photos of the community. The website has an online contact form for employers and is linked to the 
EDO email address. When an employer has a job to post or would like to recruit from the community, an inquiry email is sent. This establishes a single point of contact.

\section{Comparable Regional Projects}

The EDO was approached in March 2013 at a Grand Council Treaty 3 meeting by an organization called Shooniyaa. The EDO had referenced the CRIS project during the session and the Shooniyaa rep wanted to inform the EDO on their database project. The Shooniyaa website's description of the service shows that it is similar to the CRIS project:

The Job Connect database will focus on building a database of the job ready Aboriginal workers and connect them with employers and job opportunities within the Treaty \#3 area. The database will encourage job seekers to identify their qualifications, education and skill set and request that employers complete organizational profiles and post job vacancies. We aspire to meet the demands of employers in the Treaty \#3 area and promote the untapped Aboriginal labour pool (Shooniyaa Job Connect, 2013).

Shooniyaa manages all data but information is not available to community administration and stats are reported to HRSDC.

Bimose Tribal Council's proposal, discussed at the beginning of this paper, was approved but has had issues around sustainability. The proposal included internal salaries and administration costs. Employees would be hired to go to each community and compile the data. There were questions from the funders on whether the communities would be able to maintain data over the long-term. In contrast, ELFN has built its own capacity to manage this database whereas Bimose would have access to the personal information of the members.

\section{Launch}

The official launch was hosted in late September 2013. The Ogichidaa Warren White, Grand Chief of Grand Council Treaty \#3, was in attendance and gave opening remarks. ELFN Chief Arnold Gardner gave a welcoming message to the 48 employers in attendance. During his speech, he stated “

It's going to be a competition for these jobs but as long as we have a relationship, we can look at everyone in an equal way, as an equal opportunity. That's all we're looking for. Sometimes you have to break down a system. It's about time they knew what we're about in this community (Thompson, 2013).

Mr. Saulnier and the EDO presented the system. The process presented to employers was to contact the EDO, either through the website or through the Band Office. The EDO gathered information on what pre-requisites and education level the employer was seeking. The EDO reviewed the database, which had options to search skills and refer back to the member's resume. The resume was then generated in a uniform template, which the EDO emailed immediately or 
after calling the member to see if they would be interested in this opportunity. Resumes would be sent via email either in a group or separately. The employer could then contact the member directly, with the EDO offering to follow up at a later point to see if there was a hire.

Throughout the entirety of the CRIS project, the key tagline was always Eagle Lake's greatest assets are the people. Therefore, a cross-section of members were featured during the presentation, including the community lawyer, a hard rock miner, the former Deputy Police Chief, B.Admin professionals, CWB welders, and housing interns. Members were showcased with their accomplishments and a few members spoke on their own behalf, one stating: "It's time for us as Anishnaabe people to let go of our past misfortunes and excel into our imminent potential. We have equipped ourselves with the necessary skills and tools to make ourselves a competitive workforce".

Over the following months, the EDO met with 30 employers. Members that were struggling had secured local and regional employment. Relationships had been built with employers in various fields and sizes. This success was recognized in surrounding communities; the CRIS project, RDR and ELFN were featured in Northern Ontario Business magazine and the Dryden Observer and ELFN won Project of the Year from the Patricia Area Community Endeavours after the final report was submitted.

\section{Conclusion}

ELFN and RDR, after completing the CRIS project officially, have remained in close contact to strategize Phase 2 of the CRIS project.

Bimose secured funding from AANDC to administer their proposed CRIS project in eight of their communities. The proposed start date was April 2014. RDR will need additional support when working with the communities selected.

ELFN will be applying to FedNor for a two year youth intern. The Kenora FedNor contact was in attendance at the CRIS launch and expressed interest in this phase. This intern will continue maintaining the database, recruiting more members into the system, coordinating an off-reserve membership marketing program, participating in meetings with industry partners, and supporting the CRIS regional expansion by travelling with RDR to the new First Nations communities.

First Nations communities have several advantages in developing a skills inventory many. 1) It is attainable to capture a high percentage of the labour pool within the inventory because of the small population size. 2) The long term maintenance of the database can be assured by assigning it to a member of the band administration that presently assists members with resumes and training. Incorporating the CRIS program as the system for them to work within, rather than as an additional system, results in no change in workload. 
It was always ELFN's intention to not only be the pilot site for this initiative but to be the champions and long-term partners. A proactive solution was needed to engage with industry and ensure that ELFN's membership secured quality employment.

\section{Author biography}

Devon MacKinnon-Ottertail is a band member of Lac La Croix First Nation. She worked as the Economic Development \& Community Planner for Eagle Lake First Nation from 2012-2014 before accepting a new position. She is currently a Philanthropy Associate with Lakehead University in Thunder Bay, Ontario.

Devon has completed the University of Waterloo's Year 1 and 2 courses in community economic development and has obtained her Certificate in Local Government: Community Economic Development from Dalhousie University. She is a member of CANDO and EDAC.

Devon is an avid community volunteer and is mother to a teenage daughter.

\section{References}

Thompson, J. (2013, October 2). Eagle Lake First Nation unveils employment portal. The Dryden Observer, 5. Retrieved from http://www.runningdeerresources.com/wpcontent/uploads/2016/08/2-NAIW-News-Articles.pdf

Eagle Lake Development Corporation (2013). Home page. Retrieved from http://www.eaglelakedevelopment.com/

Shooniyaa Job Connect (2013). About Us. Retrieved from http://shooniyaajobconnect.com/ 